\title{
Including spatial variability in Monte \\ Carlo simulations of pesticide leaching
}

Bertrand Leterme ${ }^{a, *}$, Marnik Vanclooster, Ton van der Linden, Aaldrik Tiktak, Mark D.A. Rounsevell

${ }^{a}$ Dept. of Geography, Université catholique de Louvain, Pl. L. Pasteur, 3, B-1348 Louvain-la-Neuve, Belgium

* Corresponding author: E-mail: leterme@geog.ucl.ac.be; Tel.: +32 1047 28 42; Fax: +3210472877

\section{Supporting information}

Table A1: Reproducibility of the Monte Carlo analysis and the effect of truncation $(N=50)$.

\begin{tabular}{|c|c|c|c|c|c|c|c|c|}
\hline \multicolumn{2}{|l|}{ Seed number } & 1 & 2 & 3 & 4 & 5 & 6 & 1 \\
\hline \multicolumn{2}{|l|}{ Percentiles of PDF } & $5-95$ & $5-95$ & $5-95$ & $5-95$ & $5-95$ & $5-95$ & $1-99$ \\
\hline \multicolumn{9}{|l|}{ truncation for DT50 } \\
\hline \multirow[t]{3}{*}{$80^{\text {th }}$ percentile in space } & Min. & .0015 & .0014 & .0013 & .0016 & .0015 & .0015 & .0030 \\
\hline & Median & .0031 & .0035 & .0029 & .0031 & .0034 & .0032 & .0071 \\
\hline & Max. & .0092 & .0087 & .0070 & .0062 & .0077 & .0066 & .0182 \\
\hline \multirow[t]{3}{*}{ Part of the catchment with } & Min. & 6.7 & 5.7 & 7.0 & 6.1 & 6.1 & 6.0 & 9.2 \\
\hline & Median & 8.9 & 8.5 & 8.6 & 8.4 & 8.8 & 8.8 & 12.0 \\
\hline & Max. & 10.6 & 11.1 & 11.2 & 10.1 & 11.0 & 10.8 & 15.2 \\
\hline
\end{tabular}




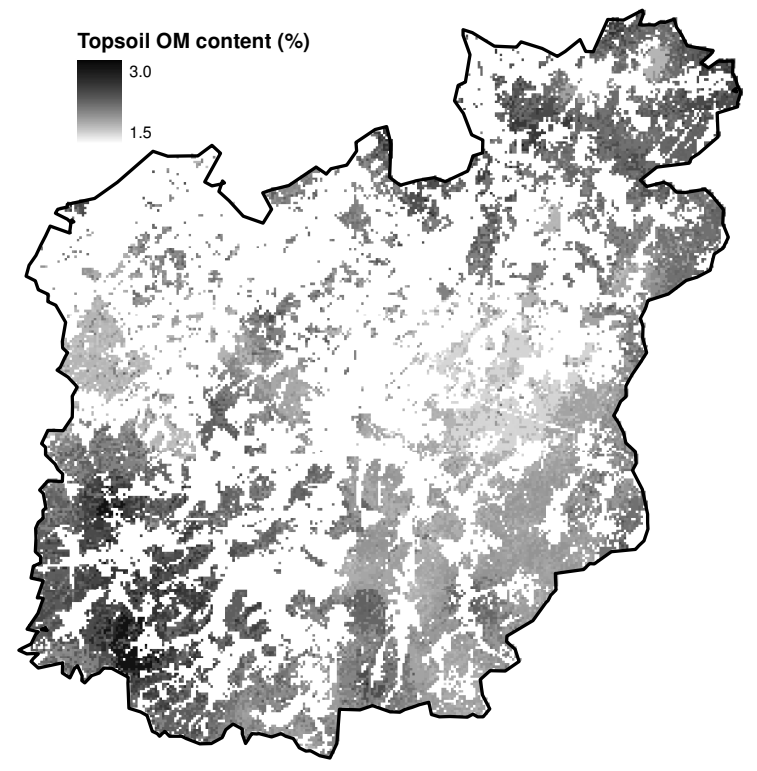

Figure A1: Organic matter content $(\%)$ in the surface horizon. White areas are non-arable land. 


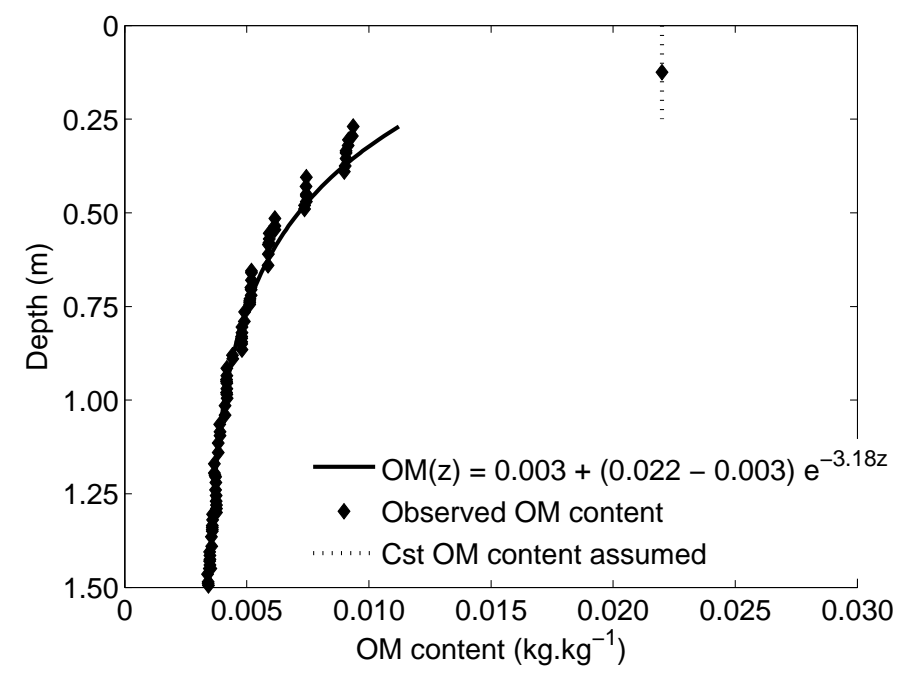

Figure A2: Average OM content profile observed in the study area and fit to the data from $0.25 \mathrm{~m}$ to the bottom of the soil profile. 